\title{
Cortical laminar distribution of $\beta$-amyloid deposits in five neurodegenerative disorders
}

\author{
Richard A. Armstrong \\ Vision Sciences, Aston University, Birmingham, United Kingdom
}

Folia Neuropathol 2020; 58 (1): 1-9
DOI: https://doi.org/10.5114/fn.2020.94001

\begin{abstract}
Alzheimer's disease neuropathologic change (ADNC) in the form of $\beta$-amyloid (AB) deposits occurs not only in Alzheimer's disease (AD) and Down's syndrome (DS) but also as a 'co-pathology' in several disorders including dementia with Lewy bodies (DLB), corticobasal degeneration (CBD), and chronic traumatic encephalopathy (CTE). To determine whether cortical laminar degeneration, as measured by $A \beta$ deposition, is similar in different disorders, changes in density of the diffuse, primitive, and classic morphological subtypes of $A \beta$ deposit were studied across all cortical layers in the frontal and temporal cortex in $A D, D S, D L B, C B D$, and CTE using quantitative analysis and polynomial curve fitting. In $A D, C T E$, and $D L B$, the diffuse $A \beta$ deposits were distributed most frequently in the upper cortical layers, distribution being more variable in $D S$ and $C B D$. In all disorders, the primitive $A \beta$ deposits were distributed primarily in the upper layers, but in $D L B$, a bimodal distribution with peaks of density in upper and lower layers was evident in some gyri. The distribution of the classic deposits varied both within and among disorders. The many similarities in laminar distribution among disorders suggest common patterns of cortical degeneration. Where differences occur, they may reflect variations in the 'prion-like' propagation of $A \beta$ along anatomical pathways in the different disorders.
\end{abstract}

Key words: Alzheimer's disease neuropathologic change (ADNC), $\beta$-amyloid (AB), cortical laminar distribution, neurodegenerative disorders, cortical degeneration.

\section{Introduction}

Alzheimer's disease neuropathologic change (ADNC) in the form of $\beta$-amyloid $(A \beta)$ deposits occurs in a variety of neuropathological settings $[43,56]$. Hence, $A \beta$ is a 'signature' pathological lesion of Alzheimer's disease (AD) $[45,55]$ and also plays a significant role in the pathology of Down's syndrome (DS) $[12,31,48,57]$. In addition, $A \beta$ deposits have been reported as a 'co-pathology' in many neurodegenerative disorders including in some cases of dementia with Lewy bodies (DLB) [14], Parkinson's disease (PD) [59], Pick's disease (PiD) [59], corticobasal degeneration (CBD) [6,59], amyotrophic lateral sclerosis (ALS) [36], progressive supranuclear palsy (PSP) [59], and chronic traumatic encephalopathy (CTE) [66].

$A \beta$ peptides are generated in brain by $\beta$ - and $\gamma$-secretase cleaving of amyloid precursor protein (APP), resulting in the formation of aggregated protein deposits $[35,40]$. A number of morphological types of $A \beta$ deposit have been described in histological sections in $A D$ and $D S$, but the majority can

\section{Communicating author}

Dr Phil. Richard A. Armstrong, Vision Sciences, Aston University, Aston Street, B4 7ET, Birmingham, United Kingdom,

phone: +441212044102, e-mail: R.A.Armstrong@aston.ac.uk 
be classified into three subtypes $[3,26]$. First, diffuse ('pre-amyloid') deposits are closely associated with neuronal cell bodies, and may be the earliest type to develop $[1,3,4]$. Second, primitive ('neuritic') deposits are more mature deposits which incorporate dystrophic neurites (DN) [3]. Third, classic ('densecored') A $\beta$ deposits consist of a distinct central 'core' surrounded by a 'corona' of DN and are frequently located adjacent to prominent blood vessels [5]. In $A D$, all three types of $A \beta$ deposit are distributed unevenly across the cortex with peaks of density in different cortical layers, the primitive and classic $A \beta$ deposits often reaching maximum density in the upper and lower layers respectively while the diffuse deposits have a more variable distribution $[2,8]$.

A previous study [10] investigated the spatial patterns of $A \beta$ deposits in the upper cortex parallel to the pia mater and found considerable similarities in their pattern of clustering in different disorders. The laminar distribution of $A \beta$ deposits may indicate the pattern of degeneration across the cortical layers and has been studied quantitatively in $\operatorname{AD}[2,8]$. The specific objective of this study was to directly compare laminar distributions of $A \beta$ deposits in five neurodegenerative disorders including not only $A D$ but also CBD, DLB, DS, and CTE which have been less studied quantitatively to determine whether there were differences associated with variations in the clinical and pathological setting. Hence, AD, CBD, and CTE are 'tauopathies' [32] in which the deposition of abnormal forms of the microtubule-associated protein (MAP) tau in the form of neurofibrillary tangles (NFT), glial inclusions (GI), and dot-like grains (DLG) is a 'signature' pathological feature [47]. By contrast, DLB is a 'synucleinopathy' in which the misfolded forms of the synaptic protein $\alpha$-synuclein are deposited as Lewy bodies (LB), Lewy neurites (LN), and Lewy grains (LG) $[32,65]$. In DS, increased $A \beta$ deposition may result from triplication of the APP gene [60], while in CTE, $A \beta$ deposition may be a consequence of traumatic brain injury (TBI) $[30,44,50,66]$.

\section{Material and methods \\ Cases}

Demographic data and diagnostic criteria for the five disorders are listed in Table I [54,55,68]. Informed consent was given for the removal of all brain tissue according to the 1996 Declaration of Helsinki (as modified Edinburgh 2000). Case material for $A D, C B D, D L B$, and $D S$, in the form of original microscope slides, was obtained from the Brain Bank, Department of Neuropathology, Institute of Psychiatry, King's College, London, UK. By contrast, because of its scarcity, case material for CTE was obtained from Boston University's CTE Center (VA-BU-CLF Brain Bank) as a series of scanned microscope images (Aperio Image-Scope Software, Leica Biosystems Inc. Buffalo Grove, IL, USA) [17,18]. To check whether determination of laminar distribution was affected by observation of scanned images rather than the original slides, a random sample of regions from the $A D$ cases was also studied both from microscope slides and from scanned images, no differences in distribution being detected.

\section{Histological methods}

Blocks of frontal cortex, at the level of the genu the of corpus callosum and temporal cortex, at the level of the lateral geniculate nucleus, were taken from

Table I. Summary of demographic details, signature pathology, associated co-pathologies, and diagnostic criteria in the disorders studied

\begin{tabular}{|lcccccc|}
\hline Disorder & $N$ & Mean age (SD) & $M: F$ & Signature lesion & $\begin{array}{c}\text { Additional } \\
\text { pathology }\end{array}$ & Diagnostic criteria \\
\hline AD & 10 & $78.2(8.3)$ & $3: 7$ & A $\beta$ deposits & EN, GVC, NFT & NINCDS/ADRDA/CERAD \\
\hline CBD & 4 & $62.5(8.01)$ & $2: 2$ & NFT & AP, GI, EN & NIH-ORD \\
\hline CTE & 6 & $71.6(8.2)$ & $6: 0$ & NFT & DN, DLG & McKee et al. [53] \\
\hline DLB & 8 & $71.5(3.40)$ & $8: 0$ & LB & LN, LG & CDLB \\
\hline DS & 11 & $40.7(4.03)$ & $6: 5$ & A 3 deposits & NFT & By karyotype \\
\hline
\end{tabular}

$A D$ - Alzheimer's disease, CBD - corticobasal degeneration, CTE - chronic traumatic encephalopathy, DLB - dementia with Lewy bodies, DS - Down's syndrome, $A P$ - astrocytic plaques, DN - dystrophic neurites, DLG - dot-like grains, EN - enlarged neurons, GVC - granulovacuolar change, $L B$ - Lewy bodies, $L G$ - Lewy grains, LN - Lewy neurites, NFT - neurofibrillary tangles, NINCDS/ADRDA - National Institute of Neurological and Communicative Disorders and Stroke and the Alzheimer Disease and Related Disorders Association [68], CERAD criteria - Consortium to Establish a Registry of Alzheimer Disease [55], NIH-ORD - National Institute of Health-Office of rare disorders, CDLB - Consortium on Dementia with Lewy bodies [54], N-number of cases studied, $M-$ male, $F-$ female, $S D$ - standard deviation 
each case to study the superior frontal gyrus (SFG) (B8), lateral-occipito temporal gyrus (LOT) (B36), and parahippocampal gyrus (PHG) (B28), gyri which frequently have high densities of $A \beta$ deposits in $A D$ and related disorders $[2,6,12,14]$. Tissue was fixed in $10 \%$ phosphate buffered formal-saline and embedded in paraffin wax. $7 \mu \mathrm{m}$ coronal sections were stained with rabbit polyclonal antibodies raised against $A \beta_{42}$ $[64,66]$. Sections were also stained with hematoxylin. The antibodies clearly revealed the diffuse, primitive, and classic subtypes of $A \beta$ deposit and were identified in the sections using previously defined criteria [3,26] (Fig. 1). Hence, diffuse $A \beta$ deposits were 10-200 $\mu \mathrm{m}$ in diameter, irregular in shape with diffuse boundaries, and were lightly immunolabelled. Primitive A $\beta$ deposits were 20-60 mm in diameter, well demarcated, more symmetrical in shape, and strongly immunolabelled, while the classic $A \beta$ deposits were $20-100 \mathrm{~mm}$, comprising a distinct and strongly immunolabelled central 'core' surrounded by a 'corona' of DN.

\section{Morphometric methods}

The laminar distribution of the $A \beta$ deposits in each gyrus was studied using methods described previously $[8,28]$. Hence, five traverses extending from the pia mater to the edge of the white matter were located at random locations along each gyrus where significant densities of $A \beta$ deposits were present. All diffuse, primitive, and classic $A \beta$ deposits were counted in $200 \times 1000 \mu \mathrm{m}$ sample fields arranged contiguously along the traverse, the larger dimension of the field orientated parallel with the surface of the pia mater. In AD, CBD, DLB, and DS, an eye-piece micrometer was used as the sample field and was moved down each traverse one step at a time from the pia mater to the edge of the white matter. In CTE, the sample fields were superimposed over the scanned images using either the draw or rectangle options $[17,18]$. Histological features of the section were used to correctly position the field. The mean of the counts from the five traverses was calculated to study variations in density of histological features across each cortical gyrus.

\section{Data analysis}

The degree of cortical degeneration present in many gyri, especially in $A D$ and $C T E$, made laminar identification difficult especially in the SFG in all dis-

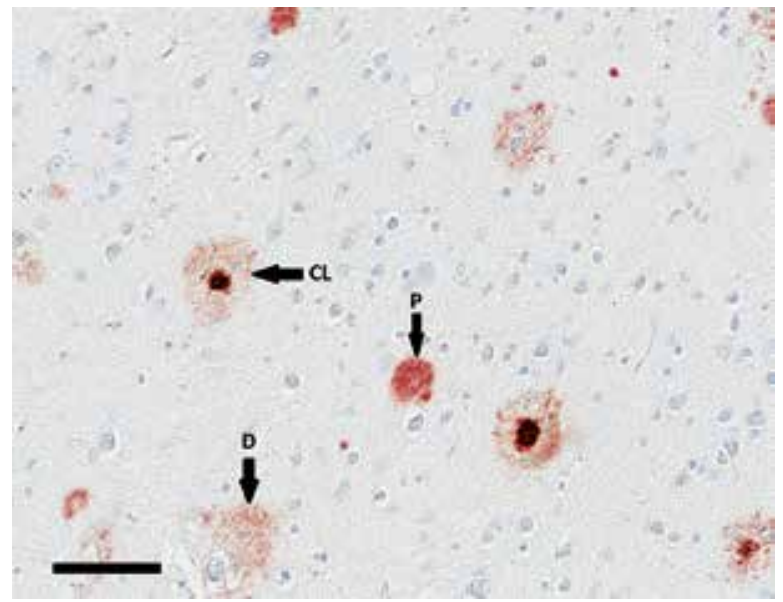

Fig. 1. The three morphological subtypes of $\beta$-amyloid $(A \beta)$ deposits observed in a case of chronic traumatic encephalopathy (CTE): (A) diffuse (D), (B) primitive (P), (C) classic deposit (CL) $\left(A \beta_{42}\right.$ immunostaining, $\mathrm{H} / \mathrm{E}$, bar $\left.=100 \mu \mathrm{m}\right)$.

orders because it exhibits a heterotypical structure, i.e., six layers cannot always be clearly identified and vary in prominence from case to case [8]. In addition, $A \beta$ deposits appeared to exhibit complex patterns of distribution across the cortex rather than being confined to individual layers. Instead, variations in density of $A \beta$ deposits with distance across the cortex were analyzed using a polynomial curve-fitting procedure (STATISTICA software, StatSoft Inc., 2300 East 14th St, Tulsa, OK, 74104, USA) [2,63]. For each gyrus, polynomials of order 1, 2, 3 up to the $4^{\text {th }}$ order were fitted successively to the data. With each fitted polynomial, the correlation coefficients (Pearson's $r$ ), regression coefficients $(\beta)$, standard errors (SE), values of $t$, and the residual mean square (MS) were obtained. A polynomial was accepted as the 'best' fit when either a non-significant value of $F$ was obtained for the next higher order polynomial or there was little gain in explained variance [58]. As a large number of statistical tests were performed without pre-planned hypotheses, the Bonferroni correction was applied to each set of comparisons, i.e., among deposit types within a disorder, among disorders, and among individual disorders for each type of deposit [7]. Where significant changes in density occurred across the cortex, the analyses were used to establish the approximate location of any significant peaks. In the majority of gyri, there was either a single density peak in the upper or lower cortex (unimodal distribution), corresponding to layers IIII 
or $\mathrm{V} / \mathrm{VI}$ respectively, or two peaks in the upper and lower cortex (bimodal distribution).

\section{Results}

Examples of the laminar distributions of $A \beta$ deposits observed are shown in Figures 2 and 3. Figure 2 shows the distribution of $A \beta$ deposits in the

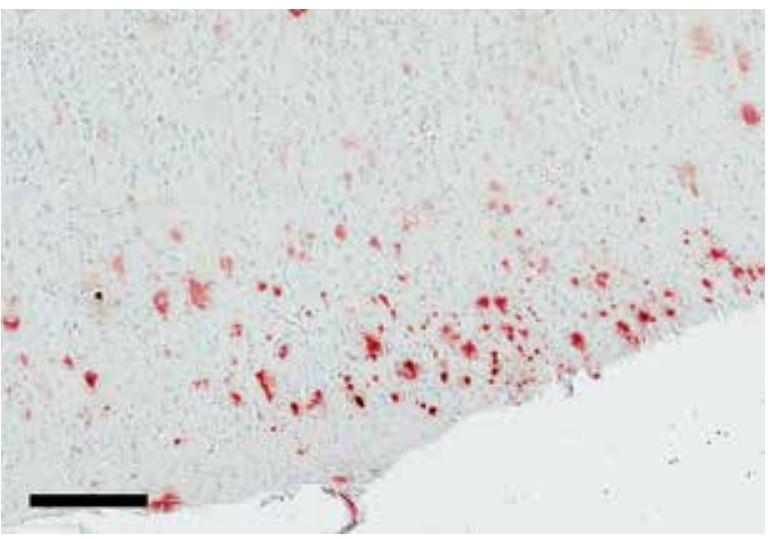

Fig. 2. Laminar distribution of the $\beta$-amyloid $(A \beta)$ deposits across the lateral occipito-temporal gyrus (LOT) in a case of chronic traumatic encephalopathy (CTE) with Alzheimer's disease neuropathologic change (ADNC). Diffuse, primitive, and rare classic $A \beta$ deposits are present in the upper cortical layers together many $A \beta$-immunopositive neuronal cell bodies $\left(A \beta_{42}\right.$ immunostaining, $\mathrm{H} / \mathrm{E}$, bar $=500 \mu \mathrm{m}$ ).

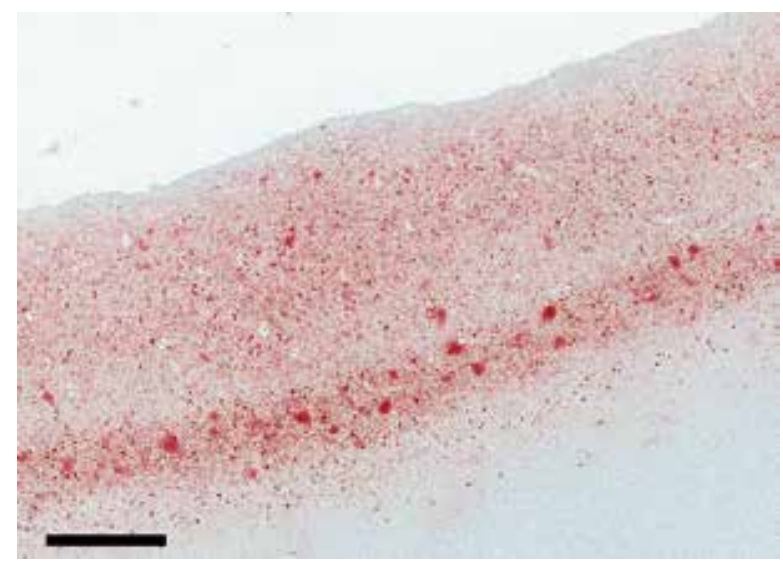

Fig. 3. Laminar distribution of the $\beta$-amyloid $(A \beta)$ deposits across the superior frontal gyrus (SFG) in a case of dementia with Lewy bodies (DLB). $A \beta$ deposits are present largely in the lower cortical layers with a few diffuse deposits scattered in the upper cortex $\left(A \beta_{42}\right.$ immunostaining, $\mathrm{H} / \mathrm{E}$, bar $=500 \mu \mathrm{m})$.
LOT of a case of CTE located primarily in the upper cortex and associated with many $A \beta$-immunolabelled cell bodies. By contrast, Figure 3 shows the distribution of $A \beta$ deposits in the SFG of a case of DLB affecting the lower layers with only a few scattered diffuse deposits in the upper layers.

Examples of the polynomial curve fitting procedure in the SFG of a case of AD are shown in Figure 4. The distribution of the diffuse $A \beta$ deposits was fitted by a third-order polynomial $(r=0.70, p<0.05)$, suggesting a bimodal distribution, high densities being present in the superficial layers and a density peak in the lower cortex. By contrast, the primitive $A \beta$ deposits were fitted by a first-order linear regression $(r=0.82, p<0.01)$, with the highest density of deposits in the upper cortex, and with a linear decline in density across the cortex. The classic $A \beta$ deposits were fitted best by a third-order polynomial $(r=0.64, p<0.05)$, and although there was less change in density compared with the diffuse and primitive deposits, the greatest densities were present in the upper cortex.

A summary of the frequencies of the different types of laminar distribution of the diffuse, primi-

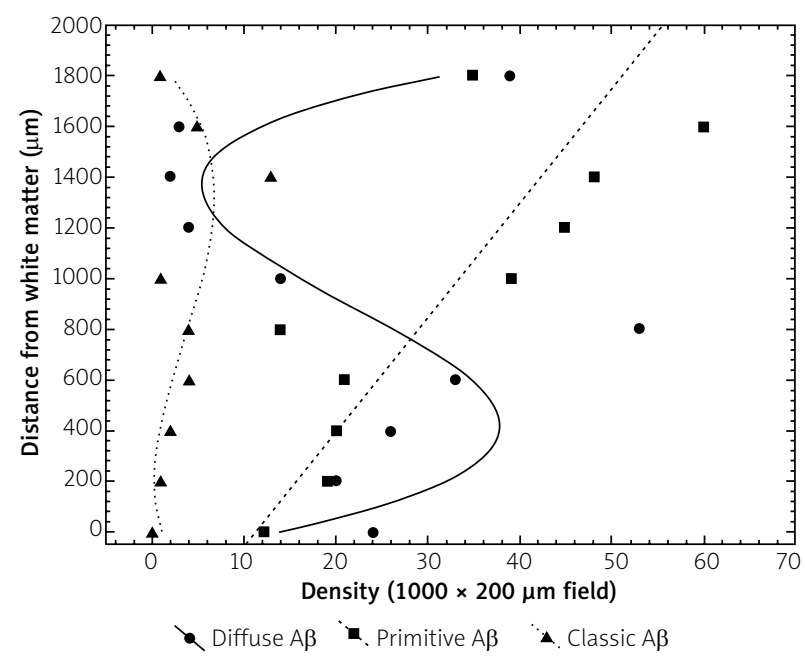

Fig. 4. Quantitative analysis of the laminar distribution of the diffuse, primitive and classic $\beta$-amyloid $(A \beta)$ deposits in the superior frontal gyrus (SFG) in a case of Alzheimer's disease (AD). Curves of best fit: Diffuse deposits: third-order polynomial $(r=0.70, p<0.05$ primitive deposits: first-order polynomial $(r=0.82$, $p<0.01$ ), classic deposits: third-order polynomial $(r=0.64, p<0.05)$. 
Table II. Cortical laminar distributions of the diffuse, primitive, and classic $\beta$-amyloid $(A \beta)$ deposits in five neurodegenerative disorders

\begin{tabular}{|c|c|c|c|c|c|c|}
\hline Disorder & $\begin{array}{l}\mathrm{A} \beta \text { deposit } \\
\text { subtype }\end{array}$ & $N$ & $\begin{array}{l}\text { Upper } \\
\text { cortex }\end{array}$ & $\begin{array}{l}\text { Lower } \\
\text { cortex }\end{array}$ & Bimodal & NS \\
\hline \multirow[t]{3}{*}{$A D$} & Diffuse & 33 & 14 & 5 & 4 & 10 \\
\hline & Primitive & 33 & 28 & 0 & 3 & 2 \\
\hline & Classic & 32 & 8 & 7 & 8 & 9 \\
\hline \multirow[t]{3}{*}{ CBD } & Diffuse & 6 & 1 & 2 & 2 & 1 \\
\hline & Primitive & 6 & 5 & 1 & 0 & 0 \\
\hline & Classic & 6 & 2 & 0 & 2 & 2 \\
\hline \multirow[t]{3}{*}{ CTE } & Diffuse & 25 & 10 & 2 & 5 & 8 \\
\hline & Primitive & 23 & 9 & 1 & 1 & 12 \\
\hline & Classic & 20 & 3 & 4 & 1 & 12 \\
\hline \multirow[t]{3}{*}{ DLB } & Diffuse & 17 & 11 & 1 & 5 & 0 \\
\hline & Primitive & 17 & 9 & 1 & 7 & 0 \\
\hline & Classic & 10 & 1 & 2 & 5 & 2 \\
\hline \multirow[t]{3}{*}{ DS } & Diffuse & 16 & 5 & 8 & 2 & 1 \\
\hline & Primitive & 14 & 9 & 2 & 2 & 1 \\
\hline & Classic & 8 & 5 & 1 & 1 & 1 \\
\hline
\end{tabular}

$A D$ - Alzheimer's disease, CBD - corticobasal degeneration, CTE - chronic traumatic encephalopathy, DLB - dementia with Lewy bodies, DS - Down's syndrome, $N$ - number of gyri studied, NS - no significant change in density across the cortex.

Comparison of spatial patterns ( $\chi^{2}$ contingency tables). *Comparisons significant after Bonferroni correction:

(1) Among deposit types within each disorder:

$A D \chi^{2}=27.35(6 D F, p<0.001)^{*}, D S \chi^{2}=6.48(6 D F, p>0.05), D L B \chi^{2}=13.37(6 D F, p<0.05), C B D \chi^{2}=9.25(6 D F, p>0.05), C T E \chi^{2}=11.05(6 D F, p>0.05)$

(2) Among all disorders:

Diffuse deposits $\chi^{2}=32.40(12 \mathrm{DF}, p<0.001)^{*}$, Primitive deposits $\chi^{2}=16.73(12 \mathrm{DF}, p>0.05)$, Classic deposits $\chi^{2}=21.96(12 \mathrm{DF}, p<0.05)$

(3) Among individual disorders:

Diffuse deposits $A D$ vs. CTE $\chi^{2}=1.20$ (3 DF, $\left.p>0.05\right)$, AD vs. DS $\chi^{2}=8.05(3 \mathrm{DF}, p<0.05), A D$ vs. $D L B \chi^{2}=8.93(3 D F, p<0.05), A D$ vs. CBD $\chi^{2}=3.63(3 D F$, $p>0.05), C T E$ vs. DS $\chi^{2}=10.52(3 \mathrm{DF}, p>0.05), C T E v s . D L B \chi^{2}=7.11(3 \mathrm{DF}, p>0.05), C T E$ vs. CBD $\chi^{2}=3.92(3 \mathrm{DF}, p>0.05), D S$ vs. DLB $\chi^{2}=9.96(3 \mathrm{DF}, p<0.05)$, $D S$ vs. $C B D \chi^{2}=2.17(3 \mathrm{DF}, p>0.05), D L B$ vs. $C B D \chi^{2}=7.38(3 \mathrm{DF}, p>0.05)$

Primitive deposits $A D$ vs. CTE $\chi^{2}=17.68(3 \mathrm{DF}, p<0.001)^{*}$, $A D$ vs. $D S \chi^{2}=5.51(3 \mathrm{DF}, p>0.05), A D$ vs. $D L B \chi^{2}=10.29(3 \mathrm{DF}, p<0.05), A D$ vs. CBD $\chi^{2}=6.41(3 \mathrm{DF}$, $p>0.05)$, CTE vs. DS $\chi^{2}=8.27(3 \mathrm{DF}, p<0.05)$, CTE vs. DLB $\chi^{2}=15.96(3 \mathrm{DF}, p<0.001)^{*}$, CTE vs. CBD $\chi^{2}=6.36(3 \mathrm{DF}, p>0.05), D S$ vs. DLB $\chi^{2}=8.27(3 \mathrm{DF}, p<0.05)$, $D S$ vs. $C B D \chi^{2}=1.52(3 D F, p>0.05), D L B$ vs. $C B D \chi^{2}=3.73(3 D F, p>0.05)$

Classic deposits $A D$ vs. CTE $\chi^{2}=6.54(3 \mathrm{DF}, p>0.05), A D$ vs. $D S \chi^{2}=4.11(3 \mathrm{DF}, p>0.05), A D$ vs. $D L B \chi^{2}=2.54(3 D F, p>0.05), A D$ vs. $C B D \chi^{2}=1.63(3 D F, p>0.05)$, CTE vs. DS $\chi^{2}=7.91(3 \mathrm{DF}, p>0.05)$, CTE vs. DLB $\chi^{2}=9.16(3 \mathrm{DF}, p<0.05)$, CTE vs. CBD $\chi^{2}=5.82(3 \mathrm{DF}, p>0.05)$, DS vs. DLB $\chi^{2}=5.85(3 \mathrm{DF}, p>0.05), D S$ vs. CBD $\chi^{2}=2.72(3 D F, p>0.05), D L B$ vs. $C B D \chi^{2}=2.79(3 D F, p>0.05)$

tive, and classic $A \beta$ deposits in the five disorders is shown in Table II. Overall, the most frequent distribution present was a density peak of $A \beta$ deposits in the upper layers, a distribution observed in 120/266 (45\%) of all gyri measured. A distribution in which A $\beta$ deposits were scattered across all layers of the cortex was the second most common, and present in $61 / 266$ (23\%) gyri. Differences in distribution were observed among $A \beta$ deposit subtypes within a disorder in $\mathrm{AD}\left(\chi^{2}=27.35, p<0.001\right)$ and $\mathrm{DLB}$ $\left(\chi^{2}=13.37, p<0.05\right)$, but only those in $A D$ remained significant after Bonferroni correction. Hence, in $A D$ the diffuse and primitive $A \beta$ deposits were more likely to be distributed in the upper cortex while the distribution of the classic deposits was more variable.

Differences in laminar distribution of the diffuse $\left(\chi^{2}=32.40, p<0.001\right)$ and classic $A \beta$ deposits $\left(\chi^{2}=21.96, p<0.05\right)$ were also evident among all disorders, but only those for the diffuse deposits were significant after Bonferroni correction. Diffuse deposits were distributed most frequently in the upper cortex in $A D, C T E$ and DLB, while responses were more variable in DS and CBD. Some differences in distribution were also observed among individual disorders. First, the primitive deposits were distributed differently in AD and CTE $\left(\chi^{2}=17.68, p<0.001\right)$, most frequently in the upper cortex in $A D$ and distributed across all cortical layers in CTE. Second, in DLB, the primitive deposits were more likely to exhibit a bimodal distribution compared with CTE $\left(\chi^{2}=15.96, p<0.001\right)$.

\section{Discussion}

Laminar distributions are similar to those reported previously with regard to $A \beta$ deposits in sporadic [2] 
and familial AD [8] and in other studies of AD reporting high densities of silver-stained senile plaques (SP) in the upper cortical layers $[22,23,28,38]$. Few studies have been carried out on the laminar distribution of $A \beta$ deposits in disorders other than $A D$, but the tau-immunoreactive pathology in CBD [15] and in CTE [19] is frequently distributed primarily in the upper cortex. By contrast, DLB is an exception in that LB pathology often exhibits a bimodal distribution but with higher densities in the lower cortex [13].

The density peak of the diffuse $A \beta$ deposits in the upper cortical layers could result from the spatial association of these deposits with large neuronal perikarya $[1,4]$. These deposits may represent an early stage in degeneration of the large pyramidal cells in the upper cortex, many of which are the cells of origin of the feed-forward cortico-cortical pathways (FF-CC) [3]. Similarly, the primitive $A \beta$ deposits commonly exhibit a density peak in the upper cortex and may result from the maturation of diffuse deposits [3] and also suggest degeneration of the FF-CC $[2,24,38]$ in all five disorders. Third, the classic 'cored' deposits occur most frequently in the lower layers in $A D[2,21]$, but the present study reveals a more variable distribution which could result from the relationship between the classic $A \beta$ deposits and cerebral blood vessels [5].

$A \beta$ deposits were more likely to be distributed across all cortical layers in AD and especially in CTE. $A D$ and CTE are both tauopathies, but CTE is associated specifically with TBI $[30,34,44,51-53,62]$ while the cause of sporadic $A D$ is likely to be more complex [11], identifying this disorder as having the most widespread laminar degeneration among those studied. The distribution of the classic A $\beta$ deposits may be of particular significance in CTE as it could reflect blood vessel damage [5]. Hence, the tau-immunoreactive pathology in CTE occurs at higher density in sulci compared with gyri, where blood vessels are densest $[17,46,52]$, accompanied by a marked perivascular distribution of NFT and AT $[51,53]$. The remaining tauopathy $C B D$ exhibits a laminar distribution which closely resembles that of $A D$, which could explain why the diagnosis of CBD is difficult, diverse presentations being present and frequently resembling other disorders such as AD [27]. DS and AD share many pathological similarities $[48,57,69]$, particular accumulations of $A \beta$ deposits being observed between the ages of 30 and 50 years [42] and this study confirms the considerable similarity in their laminar distributions. The synucleinopathy DLB exhibits some differences compared with the other disorders, and especially CTE, in the frequency of bimodal distribution of the primitive deposits, and which could be the result of two pathological processes, viz. neuronal degeneration affecting the lower layers associated with $\alpha$-synuclein-mediated LB formation [13] and degeneration affecting the upper layers.

Variation in laminar distribution could represent different stages in a dynamic process reflecting the hypothesized 'prion-like' spread of $A \beta$ among regions via neuro-anatomical pathways $[9,33,67]$. The observation that $A \beta$ deposits in $A D$ exhibit very similar spatial patterns in the tissue to PrPsc deposits in Creutzfeldt-Jakob disease (CJD) supports this hypothesis [16]. The following hypothesis is suggested to account for the observed laminar distributions. First, messenger RNA (mRNA) of amyloid precursor protein (APP) is preferentially expressed by the large pyramidal neurons [20]. Degeneration of these neurons, initially in layer III, results in increased secretion of APP and formation of diffuse A $\beta$ deposits in association with one or more neurons [4]. Second, interleukin-immunoreactive microglia (IL-Mg) have a similar laminar distribution to APP-immunoreactive neuritic plaques (NP) and contribute to the maturation of $A \beta$ to form the primitive $A \beta$ deposits [61]. Degeneration of blood vessels may be an additional factor involved in the formation of the cored classic deposits [5]. Third, A $\beta$ spreads via local interneurons from upper to lower layers to gradually affect all cortical layers, a process evident in $A D$ and most especially in CTE. Release of APP and maturation into amyloid associated with neurons in layer $V$ may also contribute to this spread in AD and CTE. Fourth, further spread of $A \beta$ occurs among cortical gyri via pathways including the short and long cortico-cortical pathways [24].

NFT also occur in greater abundance in the upper cortical layers in $A D$ [38]. Whether there is a direct link between the laminar distribution of $A \beta$ deposits and that of NFT, as suggested in AD by the amyloid cascade hypothesis (ACH), is unclear [37]. SP and NFT can develop alone in different disorders, e.g., NFT in tangle-only dementia [70] and $A \beta$ in hereditary cerebral hemorrhage with amyloidosis of the Dutch type (HCHA-D) [41]. SP and NFT may exhibit distinct but independently distributed topographic patterns in the cerebral cortex in AD [41]. In addition, Braak and 
Braak [23] showed that tau pathology occurred first in the entorhinal cortex, often in the absence of SP, whereas the subsequent spread and distribution of $\mathrm{A} \beta$ was more variable. Moreover, SP and NFT may be temporally separated in the brain [49], NFT preceding the appearance of SP in some regions. Nevertheless, it is also possible that $A \beta$ and tau formation are different consequences of degeneration of the same neurons, SP forming on the axonal terminals of NFT-containing neurons, and the respective laminar distributions of the SP and NFT may reflect this anatomical association [24].

In conclusion, cortical laminar distributions of $A \beta$ deposits in AD, CBD, CTE, DLB, and DS show considerable similarities and some differences. Differences among individual cases and disorders could reflect variations in the pathological spread of $A \beta$ among brain regions via anatomical pathways and may play a significant role in the timing and sequence of clinical symptoms exhibited by the patient.

\section{Acknowledgements}

The assistance of the Brain Bank, Institute of Psychiatry, King's College London, UK and Boston University Alzheimer's Disease Center CTE Program Brain Bank, Boston University School of Medicine, Boston, MA, USA in supplying case material for this study are gratefully acknowledged.

\section{Disclosure}

The author reports no conflict of interest.

\section{References}

1. Allsop D, Haga S, Ikeda SI, Mann DMA, Ishii T. Early senile depos its in Down's syndrome brains show a close relationship with cell bodies of neurons. Neuropathol Appl Neurobiol 1989; 15: 531-542.

2. Armstrong RA. $\beta$-amyloid $(A \beta)$ deposits and blood vessels: laminar distribution in the frontal cortex of patients with Alzheimer's disease. Neurosci Res Communs 1996; 18: 19-28.

3. Armstrong RA. $\beta$-amyloid plaques: stages in life history or independent origin? Dement Geriatr Cogn Disord 1998; 9: 227-238.

4. Armstrong RA. Diffuse $\beta$-amyloid $(A \beta)$ deposits and neurons: in situ secretion or diffusion of A $\beta$. Alz Rep 2001; 3: 289-294.

5. Armstrong RA. Classic $\beta$-amyloid deposits cluster around large diameter blood vessels rather than capillaries in sporadic Alzheimer's disease. Curr Neurovasc Res 2006; 3: 289-294.

6. Armstrong RA. Density and spatial pattern of $\beta$-amyloid $(A \beta)$ deposits in corticobasal degeneration. Folia Neuropathol 2011; 49: 14-20.
7. Armstrong RA. When to use the Bonferroni correction. Ophthal Physiol Opt 2014; 34: 502-508.

8. Armstrong RA. Laminar distribution of $\beta$-amyloid $(A \beta)$ peptide deposits in frontal lobe in familial and sporadic Alzheimer's disease. Folia Neuropathol 2015; 53: 15-23.

9. Armstrong RA. Evidence from spatial pattern analysis for the anatomical spread of $\beta$-synuclein pathology in Parkinson's disease dementia. Folia Neuropathol 2017; 55: 23-30.

10. Armstrong RA. A comparison of the spatial patterns of $\beta$-amyloid $(A \beta)$ deposits in five neurodegenerative disorders. Folia Neuropathol 2018; 56: 284-292.

11. Armstrong RA. Risk factors for Alzheimer's disease. Folia Neuropathol 2019; 57: 87-105.

12. Armstrong RA, Smith CUM. $\beta$-amyloid $(A \beta)$ deposition in the medial temporal lobe in Down's syndrome: effects of brain region and patient age. Neurobiol Dis 1995; 1: 139-144.

13. Armstrong RA, Cairns NJ, Lantos PL. Laminar distribution of cortical Lewy bodies and neurofibrillary tangles in dementia with Lewy bodies. Neurosci Res Comm 1997; 21: 145-152.

14. Armstrong RA, Cairns NJ, Lantos PL. Beta-amyloid deposition in the temporal lobe of patients with dementia with Lewy bodies: Comparison with non-demented cases and Alzheimer's disease. Dement Geriatr Cogn Disord 2000; 11: 187-192.

15. Armstrong RA, Cairns NJ, Lantos PL Laminar distribution of ballooned neurons and tau-positive neurons in corticobasal degeneration. Neurosci Res Comm 2000; 27: 85-93.

16. Armstrong RA, Lantos PL, Cairns NJ. The spatial pattern of prion protein deposits in Creutzfeldt-Jakob disease: Comparison with $\beta$-amyloid deposits in Alzheimer's disease. Neurosci Lett 2001; 298: 53-56.

17. Armstrong RA, McKee AC, Stein TD, Alvarez VE, Cairns NJ. A quantitative study of tau pathology in 11 cases of chronic traumatic encephalopathy. Neuropathol Appl Neurobiol 2016; 43: 154-166.

18. Armstrong RA, McKee AC, Alvarez VE, Cairns NJ. Clustering of tau-immunoreactive pathology in chronic traumatic encephalopathy. J Neural Transm 2016b; 124: 185-192.

19. Armstrong RA, McKee AC, Stein TD, Alvarez VE, Cairns NJ. Cortical degeneration in chronic traumatic encephalopathy and Alzheimer's disease neuropathologic change. Neurol Sci 2019; 40: 529-533.

20. Bahmanyar S, Higgins GA, Goldgaber D. Localization of amyloid $\beta$ protein messenger RNA in brains from patients with Alzheimer's disease. Science 1987; 237: 77-80.

21. Bell MA and Ball MJ. Neuritic plaques and vessels of visual cortex in aging and Alzheimer's dementia. Neurobiol Aging 1990; 11 : 359-370.

22. Braak H, Braak E, Kalus P. Alzheimer's disease: areal and laminar pathology in the occipital isocortex. Acta Neuropathol 1989; 77: 494-506.

23. Braak H, Braak E. Neuropathological staging of Alzheimer-related changes. Acta Neuropathol 1991; 82: 239-259.

24. De Lacoste M, White CL. The role of cortical connectivity in Alzheimer's disease pathogenesis: a review and model system. Neurobiol Aging 1993; 14: 1-16.

25. Delaere P, Duyckaerts C, Brion JP, Poulain V, Hauw JJ. Tau, paired helical filaments and amyloid in the neocortex: A morphometric study of 15 cases with graded intellectual status in aging 
and senile dementia of the Alzheimer type. Acta Neuropathol 1989; 77: 645-653.

26. Delaere P, Duyckaerts C, He Y, Piette F, Hauw JJ. Subtypes and differential laminar distribution of /A4 deposits in Alzheimer's disease: Relationship with the intellectual status of 26 cases. Acta Neuropathol 1991; 81: 328-335.

27. Dickson DW, Bergeron C, Chin SS, Duyckaerts C, Horoupian D Ikeda K, Jellinger K, Lantos PL, Lippa CF, Mirra SS, Tabaton M Vonsattel JP, Wakabayashi K, Litvan, I. Office of rare diseases neuropathologic criteria for corticobasal degeneration. J Neuropathol Exp Neurol 2002; 61: 935-946.

28. Duyckaerts C, Hauw JJ, Bastenaire F, Piette F, Poulain C, Rainsard V, Javoy-Agid F, Berthaux P. Laminar distribution of neocortical senile plaques in senile dementia of the Alzheimer type. Acta Neuropathol 1986; 70: 249-256.

29. Egensperger R, Weggen S, Ida N, Multhaup G, Schnabel R, Beyreuther $\mathrm{K}$, Bayer TA. Reverse relationship between $\beta$-amyloid precursor protein and $\beta$-amyloid plaques in Down's syndrome versus sporadic/familial Alzheimer's disease. Acta Neuropatho 1999; 97: 113-118.

30. Geddes J, Vowles G, Nicoll J, Revesz T. Neuronal cytoskeleta changes are an early consequence of repetitive brain injury. Acta Neuropathol 1999; 98: 171-178.

31. Glenner GG, Wong CW. Alzheimer's disease and Down's syndrome: sharing of a unique cerebrovascular amyloid fibril protein. Biochem Biophys Res Commun 1984; 122: 1131-1135.

32. Goedert M, Spillantini MG, Serpell LC, Berriman J, Smith MJ, Jakes R, Crowther RA. From genetics to pathology: tau and alpha-synuclein assemblies in neurodegenerative diseases. Phil Trans Roy Soc (Lond) B. Biol Sci 2001; 356: 213-227.

33. Goedert M, Clavaguera F, Tolnay $M$. The propagation of prion-like protein inclusions in neurodegenerative diseases. Trends Neurosci 2010; 33: 317-325.

34. Goldstein LE, Fisher AM, Tagge CA, Zhang XL, Velisek L, Sullivan JA Upreti C, Kracht JM, Ericsson M, Wojnarowicz MW, Goletani CJ, Maglakelidze GM, Casey M, Moncaster JA, Minaeva O, Moir MD, Nowinski CJ, Stern RA, Cantu RC, Geiling J, Blustajn JK, Wolozin BL, Ikezu T, Stein TD, Budson AE, Kowall NW, Chargin D, Sharon A, Samans S, Hall GF, Moss WC, Cleveland RO, Tanzi RE, Stanton PK, McKee AC. Chronic traumatic encephalopathy in blast-exposed military veterans and a blast neurotrauma mouse model. Science Transl Med 2012; 4: 134ra60.

35. Greenberg BD. The $\mathrm{COOH}$-terminus of the Alzheimer amyloid $A \beta$ peptide: Differences in length influence the process of amy loid deposition in Alzheimer brain, and tell us something about relationships among parenchymal and vessel-associated amyloid deposits. Amyloid 1995; 21: 195-203.

36. Hamilton RL, Bouser R. Alzheimer's disease pathology in amyotrophic lateral sclerosis. Acta Neuropathol 2004; 107: 515-522.

37. Hardy JA, Higgins GA. Alzheimer's disease: The amyloid cascade hypothesis. Science 1992; 256: 184-185.

38. Hof PR, Morrison JH. Quantitative analysis of a vulnerable subset of pyramidal neurons in Alzheimer's disease: 11 primary and sec ondary visual cortex. J Comp Neurol 1990; 301: 55-64.

39. Hof PR, Bouras C, Perl DP, Sparks DL, Mehta N, Morrison JH. Age-related distribution of neuropathological changes in the cerebral cortex of patients with Down's syndrome: quantitative regional analysis and comparison with Alzheimer's disease. Arch Neurol 1995; 52: 379-391.

40. Huse JT, Doms RW. Closing in on the amyloid cascade: recent insights into the cell biology of Alzheimer's disease. Mole Neurobiol 2000; 22: 81-98.

41. Hyman BT, Tanzi RE. Amyloid, dementia and Alzheimer's disease. Curr Opin in Neurol Neurosurg 1992; 5: 88-93.

42. Hyman BT, West HL, Rebeck GW, Buldyrev RN, Mantegna M, Ukleja M, Harlin S, Stanley HE. Quantitative analysis of senile plaques in Alzheimer's disease: observation of log-normal size distributions associated with apolipoprotein E genotype and trisomy 21 (Down's syndrome). Proc Natl Acad Sci USA 1995; 92: 3586-3590.

43. Hyman BT, Phelps CH, Beach TG, Bigio EH, Cairns NJ, Carrillo MC, Dickson DW, Duyckaerts C, Frosch MP, Masliah E, Mirra SS, Nelson PT, Schneider JA, Thal DR, Thies B, Trojanowski JQ, Vinters HV, Montine TJ. National Institute on Aging-Alzheimer's Association guidelines for the neuropathologic assessment of Alzheimer's disease. Alzheimers Dement 2012; 8: 1-13

44. Jordan BD. The clinical spectrum of sport-related traumatic brain injury. Nat Rev Neural 2013; 9: 222-230.

45. Khatchaturian ZS. Diagnosis of Alzheimer's disease. Arch Neurol 1985; 42: 1097-1005.

46. Kieman PT, Montinegro PH, Solomon TM, McKee AC. Chronic traumatic encephalopathy: A neurodegenerative consequence of repetitive brain injury. Sem Neurol 2015; 35: 20-28.

47. Lee VMY, Goedert M, Trojanowski JQ. Neurodegenerative tauopathies. Ann Rev Neurosci 2001; 24: 1121-1159.

48. Mann DMA, Esiri MM. The pattern of acquisition of plaques and tangles in the brains of patients under 50 years of age with Down's syndrome. J Neurol Sci 1989; 89: 169-179.

49. Mann DMA, Younis N, Jones D, Stoddart RW. The time course of pathological events in Down's syndrome with particular reference to the involvement of microglial cells and deposits of $\beta / A 4$. Neurodegen 1992; 1: 201-215.

50. Maroon JC, Winkelman R, Bost J, Amos A, Mathyssek C, Miele V. Chronic traumatic encephalopathy in contact sports: A systematic review of all reported pathological cases. PLoS One 2015; 10: e0117338.

51. McKee AC, Stein TD, Nowinski CJ, Stern RA, Daneshvar DH, Alvarez VE, Daneshvar DH, Lee HS, Wojtowicz SM, Hall G, Baugh CM, Riley DO, Kubilus CA, Cormier KA, Jacobs MA, Martin BR, Abraham CR, Ikezu T, Reichard RR, Wolozin BL, Budson AE, Goldstein LE, Kowall NW, Cantu RC. The spectrum of disease in chronic traumatic encephalopathy. Brain 2013; 136: 43-64.

52. McKee AC, Stein TD, Kieman PT, Alvarez VE. The neuropathology of chronic traumatic encephalopathy. Brain Pathol 2015; 25: 350-364.

53. McKee AC, Cairns NJ, Dickson DW, Folkerth RD, Keene CD, Litvan I, Perl D, Stein TD, Vonsattel JP, Stewart W, Tripodis Y, Crary JF, Bienick KF, Dams-O'Connor K, Alverez VF, Gordon WA, the TBI/CTE group. The first NINDS/NIBIB consensus meeting to define neuropathological criteria for the diagnosis of chronic traumatic encephalopathy. Acta Neuropathol 2016; 131: 75-86.

54. McKeith IG, Galasko D, Kosaka K, Perry EK, Dickson DW, Hansen LA, Salmon DP, Lowe J, Mirra SS, Byrne EJ, Lennox G, Quinn NP, Edwardson JA, Ince PG, Bergeron C, Burns A, Miller BL, Lovestone S, Collerton D, Jansen ENH, Ballard C, de Vos RAI, Wilcock GK, Jellinger KA, Perry $\mathrm{RH}$. Consensus guidelines for the clinical and pathological 
diagnosis of dementia with Lewy bodies (DLB): Report of the consortium on DLB international workshop. Neurology 1996; 47: 1113-1124.

55. Mirra SS, Heyman A, McKeel D, Sumi SM, Crain BJ, Brownlee LM, Vogel FS, Hughes JP, van Belle G, Berg L. The consortium to establish a registry of the neuropathological assessment of Alzheimer's disease (CERAD). II. Standardization of the neuropathological assessment of Alzheimer's disease. Neurology 1991; 41: 479-486.

56. Montine TJ, Phelps CH, Beach TG, Bigio EH, Cairns NJ, Dickson DW, Duyckaerts C, Frosch MP, Masliah E, Mirra SS, Nelson PT, Schneider JA, Thal DR, Trojanowski JQ, Vinters HV Hyman BT. National Institute on Aging; Alzheimer's Association. National Institute on Aging-Alzheimer's Association guidelines for the neuropathologic assessment of Alzheimer's disease: a practical approach. Acta Neuropathol 2012; 23: 1-11.

57. Motte J, Williams RS. Age-related changes in the density and morphology of plaques and neurofibrillary tangles in Down syndrome brain. Acta Neuropathol 1989; 77: 535-546.

58. Rafalowska J, Barcikowska M, Wen GY, Wisniewski HM. Laminar distribution of neuritic plaques in normal aging, Alzheimer's disease and Downs syndrome. Acta Neuropathol 1988; 77: 21-25.

59. Schneider JA, Watts RL, Gearing M, Brewer RP, Mirra SS. Corticobasal degeneration: Neuropathological and clinical heterogeneity. Neurology 1990; 48: 959-969.

60. Selkoe DJ. Deciphering Alzheimer's disease: the amyloid precursor protein yields further new clues. Science 1990; 248: 1058 1060.

61. Sheng JG, Griffin VST, Roystan MC, Mrak RE. Distribution of interleukin-1-immunoreactive microglia in cerebral cortical layers: implications for neuritic plaque formation in Alzheimer's disease. Neuropath Appl Neurobiol 1998; 24: 278-283.

62. Shetty AK, Mishra V, Kodali M, Hattiangady B. Blood brain barrier dysfunction and delayed neurological deficits in mild traumatic brain injury induced by blast shock waves. Front Cell Neurosci 2014; 8: 232

63. Snedecor GW, Cochran WG. Statistical methods. Iowa State University Press, Ames, lowa USA 1980.

64. Spargo E, Luthert PJ, Anderton BH, Bruce M, Smith D, Lantos PL. Antibodies raised against different proteins of $A 4$ protein identify a subset of plaques in Down's syndrome. Neurosci Lett 1990; 115: 345-350.

65. Spillantini MG, Crowther RA, Jakes R, Cairns NJ, Lantos PL, Goedert M. Filamentous $\alpha$-synuclein inclusions link multiple system atrophy with Parkinson's disease and dementia with Lewy bodies. Neurosci Lett 1998; 251: 205-208.

66. Stein TD, Montenigro PH, Alvarez VE, Xia W, Crary JF, Tripodis Y, Daneshvar DH, Mez J, Soloman T, Meng G, Kubilus CA, Cormier KA, Meng KA, Babcock K, Kiernan P, Murphy L, Nowiski CK, Martin B, Dixon D, Stern RA, Cantu RC, Kowall NW, McKee AC. Beta-amyloid deposition in chronic traumatic encephalopathy. Acta Neuropathol 2015; 130: 21-34.

67. Steiner JA, Angot E, Brunden P. A deadly spread: cellular mechanisms of -synuclein transfer. Cell Death Differ 2011; 18: 1425 1433.

68. Tierney MC, Fisher RH, Lewis AJ, Zorzitto ML, Snow WG, Reid DW, Nieuwstraten P. The NINCDS-ADRDA work group cri- teria for the clinical diagnosis of probable Alzheimer's disease. Neurology 1988; 38: 359-364.

69. Wisniewski KE, Wisniewski HM, Wen GY. Occurrence of neuropathological changes and dementia of Alzheimer's disease in Down's syndrome. Ann Neurol 1985; 17: 278-282.

70. Yamada M. Senile dementia of the neurofibrillary tangle type (tangle-only dementia): Neuropathological criteria and clinical guidelines for diagnosis. Neuropathology 2003; 23: 311-317. 